\title{
JSR EUV Resist Development toward 22nmhp Design and Beyond
}

\author{
Tooru Kimura*, Kouta Nishino, Makoto Shimizu, Yuuki Hirai, \\ Ken Maruyama and Toshiyuki Kai \\ Semiconductor Materials Laboratory, \\ Fine Electronic Materials Research Laboratories, JSR Corporation \\ 100, Kawajiri-cho, Yokkaichi, Mie, 510-8552, Japan
}

\begin{abstract}
In order to achieve targeted resist performance for EUV in practical applications, we have developed new materials such as molecular glass (MG), PAG, and acid amplifiers (AA). Protected NORIA, a molecular glass, was examined for extending resolution limits. The resist with protected NORIA showed $22 \mathrm{~nm} \mathrm{hp}$ resolutions under EUV exposure. PAG acid diffusion effect on LWR was also investigated. It was found that acid diffusion control was one of the most important factors for LWR improvement. To improve sensitivity, application of AA (acid amplifier) was investigated. The resist with AA gained $25 \%$ sensitivity improvement over the original formulation. Elemental technologies for major progress of EUV resist were made.
\end{abstract}

Keyword: lithography, EUV, molecular glass, acid amplifier, PAG

\section{Introduction}

ArF immersion lithography is capable of extending the optical lithography limit down to $4 \times n m$ hp process. Double patterning process can then lower optical lithography limits down to $2 \times \mathrm{nm} \mathrm{hp}$. Several double patterning processes were reported but they become increasingly expensive. From the technical point of view, further lithography progress would be necessary for $22 \mathrm{~nm} \mathrm{hp}$ and beyond. Extreme ultraviolet (EUV) lithography is one of the most promising candidates for next generation lithography (NGL), which can print $22 \mathrm{~nm}$ hp and beyond. Once EUV technology is in place, lithography costs would be suppressed since the high contrast of EUV permits relatively simple processes when compared to double patterning. There still exist multiple issues for EUV technology for practical application, although considerable progress in exposure tool, mask and resist were done in the last few years. Still resist remains as one of the critical items that require significant improvement. The most difficult technical issue for EUV resist is the need for simultaneous improvement in resolution, line width roughness (LWR), and sensitivity. Many research groups are developing new materials such as molecular glass (MG)1, polymer bound photo-acid generator 2,3 , high quantum yield PAG4, sensitizer5 and high absorption resin6,7 to achieve these simultaneous improvements. In this study, we focused on $\mathrm{MG}$, PAG, and acid amplifier to break the trade-off relationship among resolution, line width roughness (LWR), and sensitivity (further discussions reference the term RLS).

\section{Experimental}

\subsection{Materials}

The structure of raw materials and PAGs' anion classification in this paper are shown in Figure 1. Polyhydroxystyrene, poly[(meth acrylicacid)-co-(lactone)], protected NORIA, 
hybrid type resin and acid amplifier (AA) were synthesized in our lab. Sulfonium salts were synthesized and used as PAGs. Resist samples were obtained by mixing resin or protected NORIA, PAG, quencher, and solvent. The mixed solution was then filtered using a 0.5 um PTFE filter prior to evaluation. The resist formulations are described in Table 1.

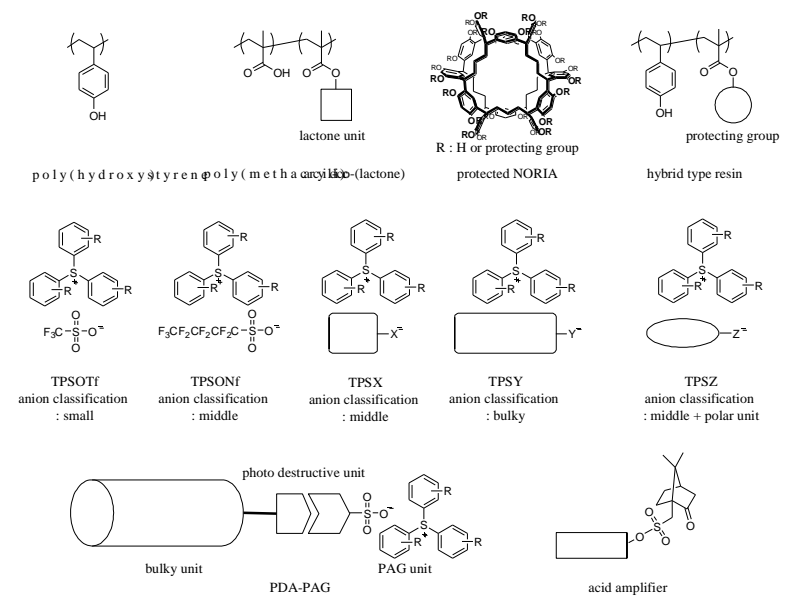

Figure 1. Structure of Raw Materials.

Table 1. Formulation of resists used in this study.

\begin{tabular}{|l|l|l|l|}
\hline Resist & Resin/MG & PAG & Additive \\
\hline Resist A & $\begin{array}{l}\text { Protected } \\
\text { NORIA }\end{array}$ & TPSX & \\
\hline Resist B & Hybrid type & TPSOTf & \\
\hline Resist C & Hybrid type & TPSONf & \\
\hline Resist D & Hybrid type & TPSY & \\
\hline Resist E & Hybrid type & TPSZ & \\
\hline Resist F & Hybrid type & TPSZ & \\
\hline Resist G & Hybrid type & TPSZ & $\begin{array}{l}\text { Acid } \\
\text { amplifier }\end{array}$ \\
\hline Resist H & Hybrid type & TPSZ & \\
\hline Resist I & Hybrid type & PDA-PAG & \\
\hline
\end{tabular}

\subsection{Measurement of acid diffusion length}

Acid diffusion length with various PAGs was investigated with the following procedure 8,9. Resist was spin-coated on a bare $\mathrm{Si}$ wafer to a 3000 angstrom film thickness after soft-bake, then exposed with a Nikon NSR S203B. Exposed resist powder was obtained by removing the resist film from the Si wafer with a razor. This powder acts as an acid source layer (Layer A in Figure 2) for the measurement of diffusion length. Resist was again coated on a new bare $\mathrm{Si}$ wafer to a 3000 angstrom film thickness (Layer B in Figure 2). Layer A was put on layer $B$ as a pellet. This stack was then baked to simulate the PEB process and acid was allowed to diffuse from layer A to layer B. The stack was then developed with $0.26 \mathrm{~N}$ TMAH solution for $60 \mathrm{sec}$. In the end, thickness loss ( $\square \mathrm{L}$ ), which is the difference between exposed and unexposed area thicknesses, was measured with DNS Lambda Ace $(\lambda=633 \mathrm{~nm})$. Acid diffusion coefficient (D) was calculated using eq. (1),

$$
\Delta \mathrm{L}=2(\mathrm{DtPEB}) 1 / 2 \mathrm{erfc}-1 \text { (Ecrit/E) }
$$

$\Delta \mathrm{L}$ is the film thickness loss, $\mathrm{D}$ is the acid diffusion coefficient, tPEB is the PEB time, erfc is the error function complement, Ecrit is the exposure dose at which film thickness loss was observed for the first time, and $\mathrm{E}$ is the exposure dose in equation (1).

Infrared spectra were recorded on a Horiba FT-720 spectrometer. ${ }^{1} \mathrm{H}$ and ${ }^{13} \mathrm{C}$-NMR spectra were obtained on a Bruker DPX-300 spectrometer. Molecular weights were determined by a gel permeation chromatography (GPC) with polystyrene calibration using a HITACHI D-7100-G equipped with column in THF at $40{ }^{\circ} \mathrm{C}$. Thermal analyses were performed on a Seiko EXSTAR 6000-TG / DTA6300 thermal analyzer at a heating rate of $10{ }^{\circ} \mathrm{C} \cdot \mathrm{min}^{-1}$ for thermogravimetric (TG) under nitrogen.

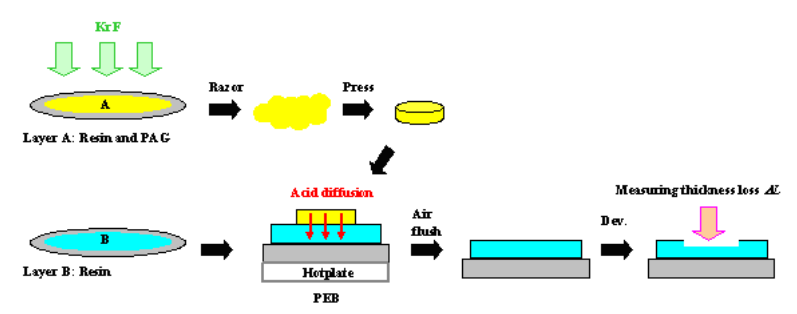

Figure2.Experimental method for acid diffusion

\section{Results and Discussion}

3.1. Technology to improve resolution

Molecular glass (NORIA)

Several molecular glasses based on star-shaped molecules ${ }^{10,11}$, calix[n]arene derivatives $^{12}$, and dendorimers ${ }^{13}$ were screened as candidates for resist materials. Cholic acid derivatives and adamantane derivatives were examined for $193 \mathrm{~nm}$ resists ${ }^{14}$. 
Cholic acid derivatives were also evaluated as EB resist ${ }^{15}$. In addition, partially t-BOC protected calix[4]resorcinarene were applied for positive-tone resist systems $^{16}$. Some polyphenol derivatives showed high resolution under EUV exposure ${ }^{17}$, however these molecules have insufficient $\mathrm{T}_{\mathrm{g}}$ (glass transition temperature) to withstand the thermal requirements of the lithographic processes.

Nishikubo et al. prepared a new polyphenol compound named NORIA, which has a three-dimensional structure, like a waterwheel, and showed unique characteristics $^{18}$. As NORIA has been confirmed to have high thermal stability due to its unique structure, the resist properties using NORIA as a molecular glass were investigated.

At first, dissolution rate of NORIA was compared to typical resins for photo resists. Dissolution rate of $100 \%$ de-protected NORIA was measured to know the possible maximum dissolution rate. Table 2 shows the dissolution rate of de-protected NORIA, polyhydroxystyrene, and poly[(methacrylic acid)-co-(lactone)] in $0.026 \mathrm{~N}$ TMAH aqueous solution.

As is evident from the relative dissolution rate values, de-protected NORIA is expected to show higher dissolution rate than polyhydroxystyrene and poly[(methacrylic acid)-co-(lactone)]. Taking this into account, we believe that protected Noria would possess strong potential to show high resolution.

Resist A using protected NORIA was exposed by an EUV exposure tool (NA: 0.30, Quadrupole). Figure 3 shows the top-down profile of Resist A where it can be clearly seen that $22 \mathrm{~nm}$ hp patterns are well-resolved. This result clearly establishes NORIA as a cutting-edge high resolution resist capable of resolving $<22 \mathrm{~nm} \mathrm{hp}$. Resolution is limited by line collapse and therefore, several studies, such as swelling suppression, profile control and additional process are currently on going.

All peaks were well assigned to the expected polymer structure. The molecular weight of polymer 3 was estimated (relative to a polystyrene standard) by gel permeation chromatography (GPC) in THF. The chromatogram of polymer 3 was a unimodal distribution with a polydispersity of 3.9 .
The weight-average molecular weight $\left(M_{\mathrm{w}}\right)$ was determined as 21,000 .

Table 2. Dissolution rate of de-protected NORIA, polyhydroxystyrene, and Poly[(methacrylic acid)-co-(lactone)]

\begin{tabular}{|c|c|c|c|}
\hline & $\begin{array}{c}\text { De-protected } \\
\text { NORIA }\end{array}$ & $\begin{array}{l}\text { Polyhydroxy } \\
\text { styrene }\end{array}$ & $\begin{array}{l}\text { Poly[(methac } \\
\text { rylicacid)-co- } \\
\text { (lactone)] }\end{array}$ \\
\hline $\begin{array}{l}\text { Stru } \\
\text {-cture }\end{array}$ & (2) & $\mathrm{OH}$ & \\
\hline $\mathrm{DR}^{*}$ & 100 & $<1$ & 10 \\
\hline
\end{tabular}

* Dissolution rate (Relative value)

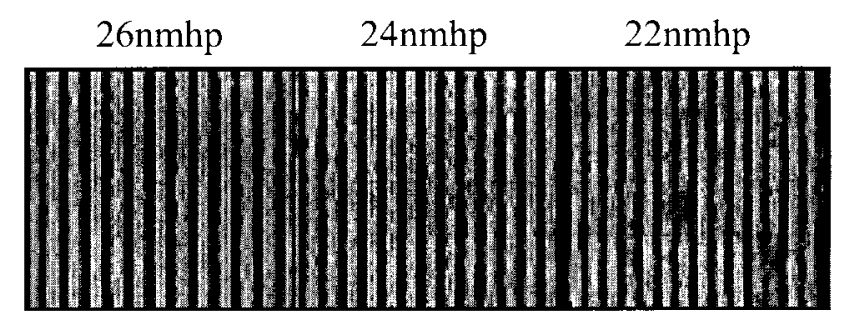

Figure 3. Top-view SEM images of line and space pattern of Resist A under EUV exposure (NA: 0.30, Quadrupole).

\subsection{Technology to Improve LWR}

\subsubsection{Acid Diffusion Control}

Various PAGs were synthesized in this study and their classification is described in Figure 1. Diffusion length of these PAGs' was determined and is summarized in Table 3.

Table 3. Acid diffusion coefficient $D$

\begin{tabular}{|c|c|c|}
\hline PAG & $\begin{array}{c}\text { Anion } \\
\text { classification }\end{array}$ & $\begin{array}{c}\text { Acid diffusion } \\
\text { coefficient } \\
\mathrm{D}\left(\mathrm{nm}^{2} / \mathrm{s}\right)\end{array}$ \\
\hline TPSOTf & Small & 110 \\
\hline TPSONf & Middle & 80 \\
\hline TPSY & Bulky & 50 \\
\hline TPSZ & $\begin{array}{c}\text { Middle with } \\
\text { polar unit }\end{array}$ & 20 \\
\hline
\end{tabular}

The acid diffusion coefficient D of TPSOTf, TPSONf, TPSY, and TPSZ were 110, 80, 50, and $20 \mathrm{~nm}^{2} / \mathrm{s}$, respectively. Many studies have already shown that an increase of PAG anion size makes acid diffusion length shorter. However, TPSZ does not have this proportional relationship 
between the anion size and acid diffusion length. It is possible that the polar unit in TPSZ has affinitive properties to the polymer backbone. and thus leading to its unique acid diffusion length behavior. Resist B, C, D, and E containing TPSOTf, TPSONf, TPSY, and TPSZ, respectively, were exposed using an EUV exposure tool (NA: 0.3, Annular). Table 4 shows the top-down profile of Resist B, C, D, and E. To see the effect of acid diffusion coefficient D on LWR, the LWR of 45 $\mathrm{nm}$ hp patterns for Resist B, C, D, and E was measured and found to be $6.4 \mathrm{~nm}, 5.8 \mathrm{~nm}, 6.0 \mathrm{~nm}$ and $4.8 \mathrm{~nm}$, respectively. This result suggests that acid diffusion control provides a good way to improve LWR.

Table 4. Top-view SEM images of line and space pattern of resist $\mathrm{B}, \mathrm{C}, \mathrm{D}$, and $\mathrm{E}$ under EUV exposure (NA: 0.3, Annular).

\begin{tabular}{|c|c|c|}
\hline Resist & PAG & LWR \\
\hline Resist B & TPSOTf & $6.4 \mathrm{~nm}$ \\
\hline Resist C & TPSONf & $5.8 \mathrm{~nm}$ \\
\hline Resist D & TPSY & $6.0 \mathrm{~nm}$ \\
\hline Resist E & TPSZ & $4.8 \mathrm{~nm}$ \\
\hline
\end{tabular}

\subsubsection{Special rinse process}

Recently, Chandhok et al. reported ${ }^{19}$ LWR reduction techniques such as vapor smoothing, hardbake, ozonaton, rinse etc. More recently, Matsunaga et al. reported ${ }^{20}$ development processes to improve LWR. In this study, a special rinse process was tested on Resist E. Z-factor helps in quantifying resist performance and is calculated with equation $(2)^{21}$.

$$
\text { Z-factor }=(\text { Resolution })^{3} \times(\text { LER })^{2} \times(\text { Sensitivity })
$$

Table 5 shows the top-down profile, resolution, LWR, sensitivity, and Z-factor of Resist E with normal rinse process and with special rinse process. The LWR of the normal rinse process and the special rinse process were $3.9 \mathrm{~nm}$ and $3.1 \mathrm{~nm}$, respectively. It was found that with the special rinse process $20 \%$ LWR improvement was gained while maintaining resolution and sensitivity. Z-factor improvement from 4.6E-08 to $3.0 \mathrm{E}-08$ represents overcoming of RLS trade off relationship with the use of ancillary rinse agents.
Table 5. Resist performance of Resist E under EUV exposure (NA: 0.30, Quadrupole).

\begin{tabular}{|c|c|c|}
\hline Resist & $\begin{array}{c}\text { Resist E } \\
\text { (Normal rinse) }\end{array}$ & $\begin{array}{c}\text { Resist E } \\
\text { (Special rinse) }\end{array}$ \\
\hline $\begin{array}{c}\text { Profile } \\
(30 \mathrm{~nm} \mathrm{hp})\end{array}$ & & \\
\hline Resolution & $26 \mathrm{~nm} \mathrm{hp}$ & $26 \mathrm{~nm} \mathrm{hp}$ \\
\hline $\begin{array}{c}\text { LWR } \\
@ 30 \mathrm{~nm} \mathrm{hp}\end{array}$ & $3.9 \mathrm{~nm}$ & $3.1 \mathrm{~nm}$ \\
\hline $\begin{array}{l}\text { Sensitivity } \\
@ \text { 30nm hp }\end{array}$ & $22.3 \mathrm{~mJ} / \mathrm{cm}^{2}$ & $23.5 \mathrm{~mJ} / \mathrm{cm}^{2}$ \\
\hline Z-factor & $4.6 \mathrm{E}-08$ & $3.0 \mathrm{E}-08$ \\
\hline
\end{tabular}

3.3 Technology to Improve Sensitivity

3.3.1 Acid amplifier

Recently, Brainard and co-workers reported22,23 one unique way of beating RLS trade-off with the application of acid amplifier (AA). In this study, we developed EUV resist using sulfonate AA. The AA structure is shown in Figure 1.

Resist F (without AA) and Resist G (with AA) were exposed using an EUV exposure tool (NA: 0.30, Quadrupole).

Table 6. Resist performance of Resist $\mathrm{F}$ and $\mathrm{G}$ under EUV exposure (NA: 0.30, Quadrupole)

\begin{tabular}{|c|c|c|}
\hline Resist & $\begin{array}{c}\text { Resist F } \\
\text { (without AA) }\end{array}$ & $\begin{array}{l}\text { Resist G } \\
\text { (with AA) }\end{array}$ \\
\hline $\begin{array}{c}\text { Profile } \\
(30 \mathrm{~nm} \mathrm{hp})\end{array}$ & & \\
\hline Resolution & $26 \mathrm{~nm} \mathrm{hp}$ & $24 \mathrm{~nm} \mathrm{hp}$ \\
\hline $\begin{array}{c}\text { LWR } \\
@ 30 \mathrm{~nm} \mathrm{hp}\end{array}$ & $4.7 \mathrm{~nm}$ & $5.5 \mathrm{~nm}$ \\
\hline $\begin{array}{l}\text { Sensitivity } \\
@ 30 \mathrm{~nm} \mathrm{hp}\end{array}$ & $30.6 \mathrm{~mJ} / \mathrm{cm}^{2}$ & $14.9 \mathrm{~mJ} / \mathrm{cm}^{2}$ \\
\hline Z-factor & $9.1 \mathrm{E}-08$ & $6.1 \mathrm{E}-08$ \\
\hline
\end{tabular}

Table 6 shows the top-down profile, resolution, LWR, sensitivity, and Z-factor of resists F and G. Sensitivity of $30 \mathrm{~nm}$ hp patterns for Resist $F$ and $G$ were found to be $30.6 \mathrm{~mJ} / \mathrm{cm} 2$ and $14.9 \mathrm{~mJ} / \mathrm{cm} 2$, respectively. It was found that resist $G$ significantly improved sensitivity compared to Resist F. Furthermore, Resist G improved Z-factor from Resist $F$ as well. This result suggests that AA has possibility to beat the RLS trade off. Certain structural modifications of AA 
have been identified that will likely result in improved performance and further optimization along these lines is on-going.

\subsubsection{Photo Destructive Anion PAG (PDA-PAG)}

Photo destructive anion PAG (PDA-PAG) was developed to control acid diffusion length. PDA-PAG contains both a photo acid generation unit and a photo destructive unit in the same molecule. Here photo acid generation happens first, followed by the decomposition of the remaining anion part. Therefore, this PAG works as a bulky anion at low dose areas consequently having short acid diffusion length. On the other hand at higher dose areas the anion is decomposed in such a way that a smaller acid is obtained that has longer diffusion length. This property matches the resist design concept of having high sensitivity and resolution at the same time. The PAG has short acid diffusion length in the border of exposed/unexposed areas which is desirable for high resolution. Long acid diffusion length in the exposed area is desirable for high sensitivity.

Resist $\mathrm{H}$ with TPSY and Resist I with PDA-PAG were exposed using an EUV exposure tool (NA: 0.30, Quadrupole). Table 7 shows the top-down profile, resolution, LWR, sensitivity, and Z-factor of Resist H and I. Sensitivity of 30nm hp patterns for Resist $\mathrm{H}$ and I were found to be $22.4 \mathrm{~mJ} / \mathrm{cm} 2$ and $16.7 \mathrm{~mJ} / \mathrm{cm} 2$, respectively. It was found that Resist I improved sensitivity compared with resist $\mathrm{H}$ while maintaining resolution and LWR. Resist I improved Z-factor compared to resist $\mathrm{H}$. This result suggests that PDA-PAG has capability to beat the RLS trade off. Further formulation optimization with PAD-PAG is on-going.

Table 7. Resist performance of Resist $\mathrm{H}$ and I by EUV exposure (NA: 0.30, Quadrupole).

\begin{tabular}{|c|c|c|}
\hline Resist & Resist H & Resist I \\
\hline PAG & TPSZ & PDA-PAG \\
\hline $\begin{array}{l}\text { Profile } \\
30 \mathrm{~nm} \mathrm{hp}\end{array}$ & & \\
\hline Resolution & $24 \mathrm{~nm} \mathrm{hp}$ & $24 \mathrm{~nm} \mathrm{hp}$ \\
\hline $\begin{array}{l}\text { LWR } \\
\text { @30 nm hp }\end{array}$ & $4.4 \mathrm{~nm}$ & $4.2 \mathrm{~nm}$ \\
\hline $\begin{array}{l}\text { Sensitivity } \\
\text { @ } 30 \mathrm{~nm} \mathrm{hp}\end{array}$ & $22.4 \mathrm{~mJ} / \mathrm{cm}^{2}$ & $16.7 \mathrm{~mJ} / \mathrm{cm}^{2}$ \\
\hline Z-factor & $5.9 \mathrm{E}-08$ & $4.0 \mathrm{E}-08$ \\
\hline
\end{tabular}

\section{Conclusion}

In this study, multiple technical progresses were done which are contributing to EUV resist improvement. Protected NORIA for resolution extension and new PAG designs to overcome the RLS trade off showed major progress. In addition to material development, post development rinse processes showed capability to improve LWR. Now multiple items to improve resist properties are ready. Results of this study will push EUV technology for practical application from the resist requirement point of view.

\section{References}

1. Daisuke Shimizu, Ken Maruyama, Akio Saitou,Toshiyuki Kai,Tsutomu Shimokawa, Koichi Fujiwara,Yukiko Kikuchi and Iwao Nishiyama,"Progress in EUV Resist Development," J. Photopolym. Sci. Tech. 20, 423 (2007).

2. Theodore H. Fedynyshyn, David K. Astolfi, Alberto Cabral, Susan Cann, Indira Pottebaum and Jeanette M. Roberts, "PAG segregation during exposure affecting innate material roughness," Proc. SPIE, 7273, 727349-1 (2009).

3. Mingxing Wang, Wang Yueh. and Kenneth E. Gonsalves, "Novel ionic photoacid generators (PAGs) and corresponding PAG bound polymers," J. Photopolym. Sci. Tech., 20, 793 (2007).

4. Hideaki Tsubaki, Tooru Tsuchihashi, Katsuhiro Yamashita, and Tomotaka Tsuchimura, "Resist materials design to improve sensitivity in EUV lithography," Proc. SPIE, 7273, 72733P-1 (2009).

5. E. Steve Putna, Todd R. Younkin, Manish Chandhok, and Kent Frasure, "EUV lithography for $30 \mathrm{~nm}$ half pitch and beyond: exploring resolution, sensitivity and LWR tradeoffs," Proc. SPIE, 7273, $72731 \mathrm{~L}-1$ (2009).

6. Roel Gronheid, Carlos Fonseca, Michael J. Leeson, Jacob R. Adams, Jeffrey R. Strahan, C. Grant Willson, and Bruce W. Smith, " EUV Resist Requirements: Absorbance and Acid Yield," Proc. SPIE, 7273, 727332-1 (2009).

7. Takahiro Kozawa, Seiichi Tagawa, Julius Joseph Santillan and Toshiro Itani, "Impact of nonconstant diffusion coefficient on latent image quality in 22 
$\mathrm{nm}$ fabrication using extreme ultraviolet lithography," J. Photopolym. Sci. Tech., 21, 421 (2008).

8. Jae Hyun Kim, Chang Ho Lee, Seok Bong Park, Won Mi Kim, Sang Sik Moon, Kyung-Mee Kim, Shi Yong Lee, Sangwoong Yoon, Young-Ho Kim, and Sang Mun Chon, "Influence of activation energy on LER in chemically amplified $\mathrm{KrF}$ photoresists," Proc. SPIE, 5376, 790 (2004).

9. Jae Hyun Kim, Yong-Ho Kim, Sang Mun Chon, Tomoki Nagai, Masahiro Noda, Yoshikazu Yamaguchi, Yutaka Makita and Hiroaki Nemoto, " Influence of acid diffusion length on line edge roughness in KrF photoresists," J. Photopolym. Sci. Tech., 17, 379 (2004).

10. Toshiaki, K., Motoko, Y., Hiroshi, K., Fujio, W., Kenji, G., and Yasuhiko S., "Creation of Low Molecular-weight Organic Resists for Nanometer Lithography," Proc. SPIE, 4345, 891 (2001).

11. Yasuhiko, S., "Organic materials for electronic and optoelectronic devices," $J$. Mater. Chem., 10, 1 (2000).

12. Tomonari, N. and Mitsru, U., "A new positive-type photoresist based on mono-substituted hydroquinone calix [8] arene and diazonaphthoquinone, " $J$. Mater. Chem., 9, 697 (1999).

13. J. Fujita, Y. Ohnishi, Y. Ochiai and S. Matsui, "Ultrahigh resolution of calixarene negative resist in electron beam lithography, " Appl. Phys. Lett., 68, 1297 (1996).

14. Jin-Baek, K., Hyo-Jin, Y., and Young-Gil, K., "Novel molecular resist based on derivative of cholic acid," Chem. Lett., 31, 1064 (2002).

15.Daiju, S., Taku, H., Hideo, H., Junichi, O., Tadashi, A., Atsuko, Y., Kyoko, K., Hiroshi, S and Hiroshi, F., "Molecular resists based on cholate derivatives for electron-beam lithography," Proc. SPIE, 6153, 61532D1 (2006).

16. Mitsuru, U., Daisuke, T., Tomonari, N., and Osamu, H., "Three-componet negative-type photoresist based on
Calix [4]resorcinarene, a cross-linker, and a photoacid generator," Chem. Mater, 10, 2230 (1998).

17. Seung Wook Chang, Da Yang, Junyan Dai, Nelson Felix, Daniel Bratton, Kousuke Tsuchiya, Young-Je Kwark, Juan-Pablo Bravo, Christopher K. Ober, Heidi B. Cao and Hai Deng. "Materials for Future Lithography," Proc. SPIE., 5753, $1-9(2005)$.

18. Hiroto, K., Rieko, H., Kouji, M, Tsutomu, Y., Noriko, C, K., and Tadatomi, N., "Molecular Waterwheel (Noria) from a Simple Condensation of Resorcinol and an Alkanedial," Angew. Chem. Int. Ed., 45, 7948 (2006).

19. Manish Chandhok, Kent Frasure, E. Steve Putna, Todd R. Younkin, Willy Rachmady, Uday Shah, and Wang Yueh, "Improvement in linewidth roughness by postprocessing," J. Vac. Sci. Technol., B 26 (6), Nov/Dec 2265 (2008).

20. Kentaro Matsunaga, Hiroaki Oizumi, Koji Kaneyama,Gousuke Shiraishi, Kazuyuki Matsumaro, Julius Joseph Santillian and Toshiro Itani, "EUV resist materials and processing at Selete," 2009 International Symposium on Extreme Ultraviolet Lithography.

21. Wallow, T., Higgins, C., Brainard, R., Petrillo, K., Montgomery, W., Koay, C., Denbeaux, G., Wood, O., Wei, Y., "Evaluation of EUV resist materials for use at the $32 \mathrm{~nm}$ half-pitch node," Proc. SPIE, 6921, 69211F (2008).

22. Robert Brainard, Seth Kruger, Craig Higgins, Srividya Revuru, Sarh Gibbons, Dan Freedman, Wang Yueh and Todd Younkin, " Kinetics, Chemical Modeling and Lithography of Novel Acid Amplifiers for Use in EUV Photoresists," $J$. Photopolym. Sci.Tech., 22, 43 (2009).

23. Robert Brainard, Craig Higgins, Seth Kruger, Srividya Revuru, Brian Cardineau, Sarah Gibbons, Dan Freedman, Harun Solak, Wang Yueh and Todd Younkin," Lithographic Evaluation and Chemical Modeling of Acid Amplifiers used in EUV Photoresists," Proc. SPIE, $\mathbf{7 3 7 3}$, 72733Q-1 (2009). 